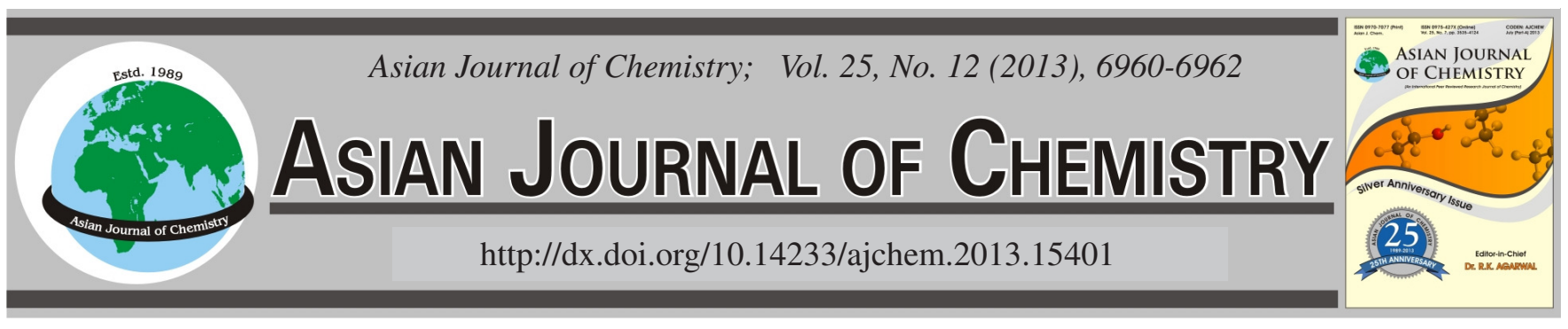

\title{
Applications of Glycidyltrimethylammonium Chloride-Modified Carbon Nanotubes
}

\author{
Wenzong Zhang ${ }^{1, *}$, Weimin Zhang ${ }^{2}$, JieJie Ren ${ }^{3}$ and Ming Yuan ${ }^{3}$
}

\begin{abstract}
${ }^{1}$ Laboratory of Cell Imaging, Henan University of Traditional Chinese Medicine, Zhengzhou 450002, P.R. China
${ }^{2}$ The First Affiliated Hospital, Henan University of Science \& Technology, Luoyang 471003, Henan Province, P.R. China

${ }^{3}$ College of Pharmacy, Henan University, Kaifeng 475004, P.R. China
\end{abstract}

*Corresponding author: Tel/Fax: +86 371 60906295; E-mail: zhangwenzong75@ sina.cn

\section{INTRODUCTION}

Carbon nanotubes (CNTs) have attracted great attention in recent years. Carbon nanotubes could be modified by diverse of methods and further assembled into various devices for different applications ${ }^{1}$. The modification of CNTs often involves the improvement of their water solubility. Ammonium functionalization of CNTs is one of efficient approaches. A number of reagnets with amino groups such as polyethyleneimine (PEI) have been grafted to CNTs. These PEIfunctionalized CNTs have many interesting applications such as gas adsorption, gene delivery and as a neural growth substrate. They can also be further assembled and modified to form superhydrophobic multilayered surfaces ${ }^{2}$. Glycidyltrimethylammonium chloride (GTMAC) is another aminocontaining composite and often be used to introduce quaternary amino groups onto several types of materials such as chitosan. The quaternized chitosan has been reported to have good water solubility, bioadhesive properties, permeation enhancing effects and high efficacy against bacteria ${ }^{3}$. Glycidyltrimethylammonium chloride-modified carbon nanotubes have been also reported recently ${ }^{4}$, but less is known about their applications. In this study, we attempt to evaluate the potential applications of GTMAC-modified CNTs viz., the assembly of layer-by-layer (LBL) films, DNA binding and antibacterial activity.

\section{EXPERIMENTAL}

Pristine multi-walled carbon nanotubes (MWNTs) were obtained from Shenzhen Nanotech Port Co. Ltd., China. GTMAC and PMMA microspheres were purchased from Sigma-Aldrich. All other chemicals are of analytical grade. The carboxylic acid modified MWNTs (denoted as MWNTs1) were obtained by the oxidization of pristine MWNTs in nitricsulfuric acid. The GTMAC-modified MWNTs were prepared according to prior report ${ }^{4}$. In brief, the $\mathrm{SOCl}_{2}$-treated MWNTs$\mathrm{COOH}$ reacted with GTMAC in DMF at $120{ }^{\circ} \mathrm{C}$ to obtain quaternary ammonium-modified MWNTs (denoted as MWNTs2). Both anionic MWNTs1 and cationic MWNTs2 could be homogeneously dispersed in water and possess the zeta potential values of -34.6 and $24.2 \mathrm{mV}$, respectively.

Layer-by-layer (LBL) assembly has been widely used in preparing CNTs-based multilayer films or core-shell microspheres by using colloidal cores as templates, onto which the uniform multilayers are deposited by electrostatics interaction or covalent bond $^{5}$. The MWNTs1/MWNTs2 planar layer-by-layer assembly on quartz slides was prepared as follows: The slide was immersed in an aqueous suspension of MWNT2 $(1 \mathrm{mg} / \mathrm{mL})$ for $5 \mathrm{~min}$. After rinsed with water and dried, MWNT2 was deposited on the slide from an aqueous suspension of MWNT2 $(1 \mathrm{mg} / \mathrm{mL})$ in the same way to finish a layer-by-layer cycle. By repeating the alternate deposition of MWNT1/MWNT2, 
multilayer film with desired MWNT layers could be fabricated. Herein, (MWNT1/MWNT2)n was used to denote the films after $\mathrm{n}$ MWNT1/MWNT2 assembly. This assembly procedure could be easily monitored by SEM images and UV/visible spectra.

DNA binding: In brief, $20 \mu \mathrm{L}$ of $50 \mathrm{ng} / \mu \mathrm{L}$ DNA (pGFP) was mixed with $20 \mu \mathrm{L}$ of different concentration MWNTs2 $(0.5,1,2$ and $4 \mathrm{mg} / \mathrm{mL}$ ) in PBS buffer ( $\mathrm{pH} 7.4)$ respectively. Then the supernatant was presented to agarose gel electrophoresis.

Antibacterial actvity: The antibacterial activity of MWNTs2 was evaluated according to prior report ${ }^{6}$. In brief, $100 \mu \mathrm{L}$ of bacteria (E. coli) suspension with concentration of $10^{5} \mathrm{~mL}^{-1}$ was added to $1 \mathrm{~mL}$ measured samples with different concentrations and the control sample. After shaking $24 \mathrm{~h}$ at room temperature, samples with bacteria suspension were put into the test tube containing $10 \mathrm{~mL}$ of PBS ( $\mathrm{pH} 7.4)$. The tubes were shaken 300 times, then $100 \mu \mathrm{L}$ of diluted suspension was spread on agar culture medium plates and incubated at $37{ }^{\circ} \mathrm{C}$ for $24 \mathrm{~h}$.

\section{RESULTS AND DISCUSSION}

The morphologies of the MWNTs1/MWNTs2 films on quartz slides with different assembly cycles observed by SEM are shown in Fig. 1(a) and (b). After one cycle of MWNTs1/ MWNTs2 adsorption, the randomly distributed MWNTs cover most of the substrate surface [Fig. 1(a)]. With an increase of the cycle numbers, the MWNT coverage increases dramatically. The nanotubes of (MWNTs1/MWNTs2) ${ }_{3}$ film almost fully cover the substrate surface [Fig. 1(b)]. Furthermore, Fig. 2 shows the UV/visible spectra tracking the MWNT1/MWNT2 film growth with the MWNT layers up to 6 on a quartz slide (three layer-by-layer cycles). The characteristic absorbance of CNTs at $260 \mathrm{~nm}$ is found to increase linearly with the growth of the film, implying the growth of the MWNT1/MWNT2 film in each assembly cycle is effective and uniform. Similarly, the stepwise growth of a MWNTs1/MWNTs2 multilayer can be extended to the PMMA microspheres. As shown in Fig. 3(a), the uncoated PMMA microspheres exhibit a smooth surface with some tiny holes observed by SEM. After MWNTs1/ MWNTs2 coating, some flocky threadlike MWNTs appear on the surfaces of the PMMA microspheres. With the increase of the assembly number, more and more MWNTs tightly wrap on the microspheres and then form an interconnected network structure, making the surface of microspheres roughness [Fig. 3(b)]. The result indicates that the electrostatic interactions between different charged MWNTs can realize the layer-by-layer assembly on the planar substrate and the spherical templates.

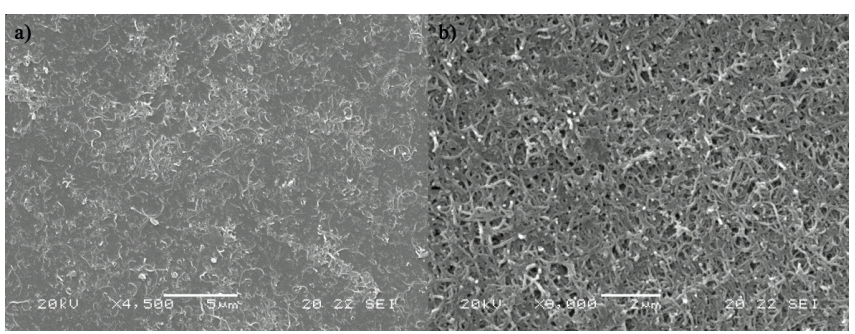

Fig. 1. SEM images of MWNT films with one (a) and three (b) MWNT layers

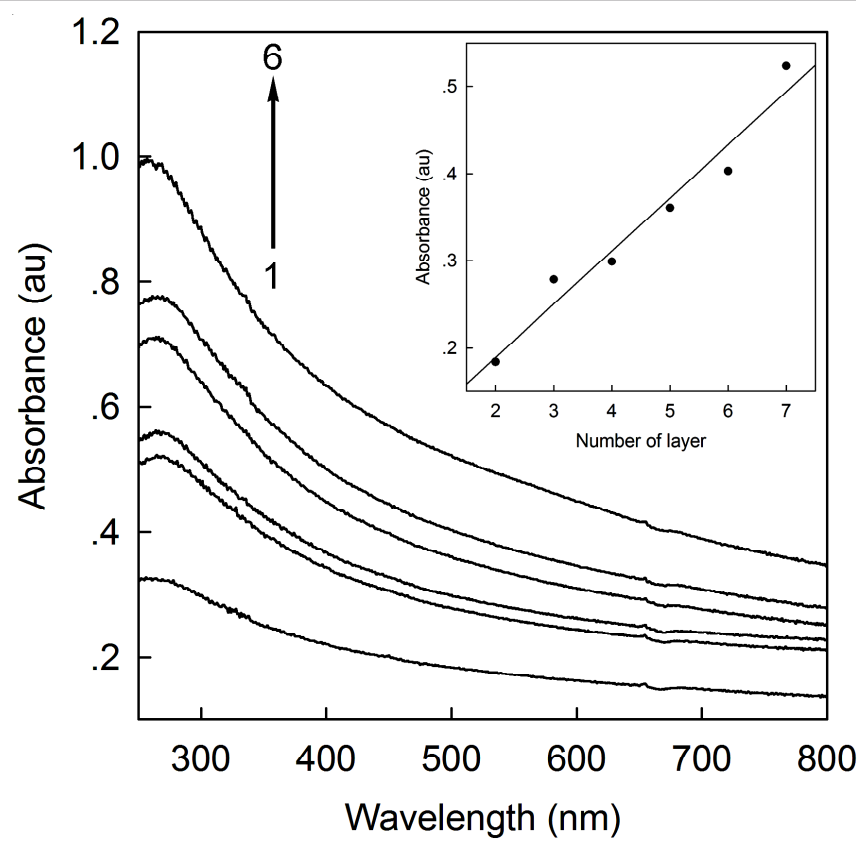

Fig. 2. UV-visible absorption spectra of MWNT1/MWNT2 multilayer films fabricated on quartz slide. Inset shows the absorbance at $260 \mathrm{~nm}$

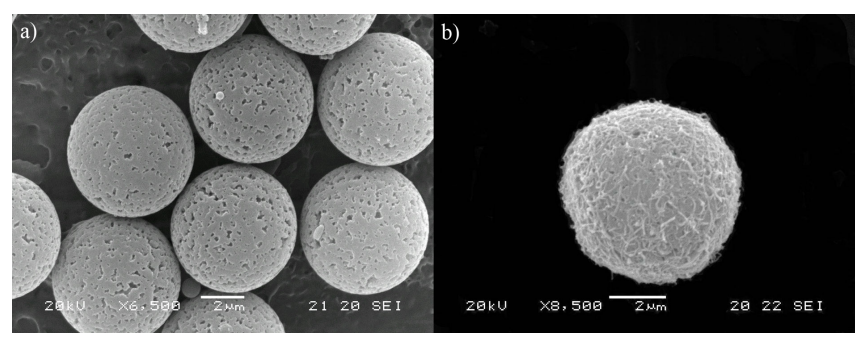

Fig. 3. SEM images of uncoated PMMA microspheres (a), PMAA microspheres coated with three MWNT1/MWNT2 multilayers (b)

It has been reported that ammonium-functionalized CNTs could bind and condense the plasmid DNA by the electrostatics interaction for the construction of CNTs-based gene delivery vectors ${ }^{7}$. Therefore, the DNA binding capability of MWNTs2 was investigated by the electrophoretic motility shift assay in the next according to prior report.

As shown in Fig. 4, comparing with the control sample with strong fluorescence emission, the fluorescence intensity of the measured sample decreased in a dose-dependent style and disappeared completely at the point of $4 \mathrm{mg} / \mathrm{mL}$ of MWNTs2. The result suggested that MWNTs2 could bind and condense the plasmid DNA. With the increasing of MWNTs2 concentration, more and more DNA was captured by MWNTs2 via electrostatic attraction, thus leading to the reduction of free DNA in the supernatant gradually.

As shown in Fig. 5, the plate used for reference sample was nearly covered by the bacterial colonies [Fig. 5(a)]. The sample containing $10 \mathrm{mg} / \mathrm{mL}$ of MWNTs 1 exhibited less colonies than the reference one [Fig. 5(b)]. Comparing with such two samples, only few bacterial colonies were found in the sample containing $1 \mathrm{mg} / \mathrm{mL}$ of MWNTs2 [Fig. 5(c)]. The result indicated that MWNTs2 had stronger antibacterial activity. Single-walled carbon nanotubes were also reported to have antibacterial activity and their antibacterial activity was mainly attributed to either a physical interaction with 


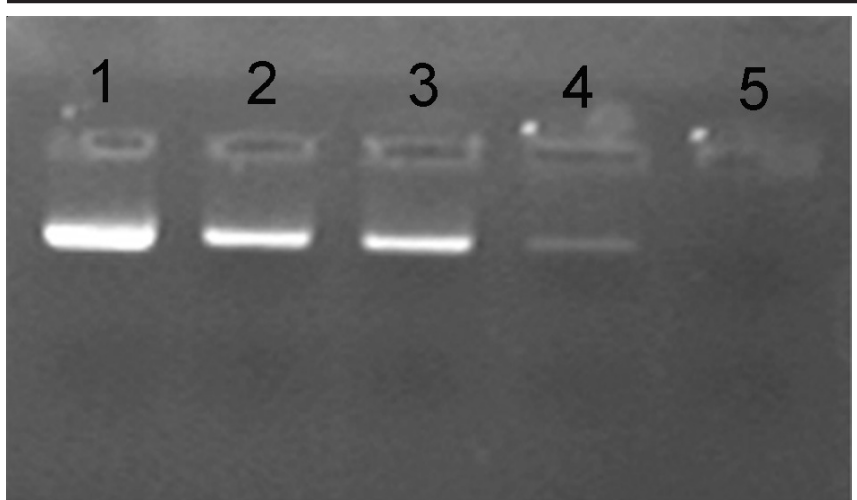

Fig. 4. Electrophoretic motility of MWNT2-DNA complexes. In all panels, lane 1 represents free DNA. All other lanes contain MWNT2 complexed to DNA at various concentrations: lane $2,0.5 \mathrm{mg} / \mathrm{mL}$; lane $3,1 \mathrm{mg} / \mathrm{mL}$; lane $4,2 \mathrm{mg} / \mathrm{mL}$; lane $5,4 \mathrm{mg} / \mathrm{mL}$

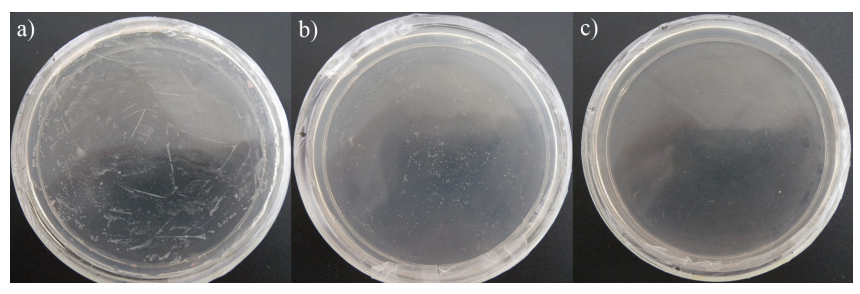

Fig. 5. Bacterial colonies of control sample (a); MWNT1 sample (10 mg/ $\mathrm{mL})(\mathrm{b}) ;$ MWNT2 sample (1 mg/mL) (c)

bacterial cells or oxidative stress that compromise bacterial cell membrane integrity ${ }^{6}$. Relative to the weak antibacterial activity of MWNTs1, it is presumed that the quaternary ammonium groups play an important role in the antibacterial effect of MWNTs2 rather than naotubes itself.

\section{Conclusion}

In summary, we have demonstrated that glycidyltrimethylammonium chloride-modified carbon nanotubes could have DNA binding and antibacterial activity and also be used for the assembly of layer-by-layer films on the planar substrate or the spherical templates, rendering them as a potential functional material used for the various scientific fields in the future.

\section{ACKNOWLEDGEMENTS}

This work was supported by grants from Natural Science Foundation of Henan Province (Grant No. 102300410180), the Foundation for University Young Key Teacher by Henan Province (Grant No. 2009GGJS-021) and Henan University (Grant No. SBGJ090708).

\section{REFERENCES}

1. J.M. Schnorra and T.M. Swager, Chem. Mater, 23, 646 (2011).

2. M. Shen, S.H. Wang, X. Shi, X. Chen, Q. Huang, E.J. Petersen, R.A. Pinto, J.R. Baker and W.J. Weber, J. Phys. Chem. C, 113, 3150 (2009).

3. Q.X. Ji, D.Y. Zhong, R. Lü, W.Q. Zhang, J. Deng and X.G. Chen, Carbohyd. Polym., 344, 1297 (2009).

4. Z. Wang, Y.D. Huang, S.S. Yue and X.Z. Bai, J. Nat. Sci. Heilongjiang Univ., 24, 787 (2007)

5. J.H. Shi, Z.Y. Chen, Y.J. Qin and Z.X. Guo, J. Phys. Chem. C, 112, 11617 (2008).

6. S. Kang, M. Pinault, L.D. Pfefferle and M. Elimelech, Langmuir, 23, 8670 (2007).

7. R. Singh, D. Pantarotto, D. McCarthy, O. Chaloin, J. Hoebeke, C.D. Partidos, J.P. Briand, M. Prato, A. Bianco and K. Kostarelos, J. Am. Chem. Soc., 127, 4388 (2005). 